Article

\title{
Gardening for Food Well-Being in the COVID-19 Era
}

\author{
Esteve G. Giraud *, Sara El-Sayed (1) and Adenike Opejin
}

check for

updates

Citation: Giraud, E.G.; El-Sayed, S.; Opejin, A. Gardening for Food Well-Being in the COVID-19 Era. Sustainability 2021, 13, 9687. https://doi.org/10.3390/su13179687

Academic Editor: Hossein Azadi

Received: 30 July 2021

Accepted: 25 August 2021

Published: 28 August 2021

Publisher's Note: MDPI stays neutral with regard to jurisdictional claims in published maps and institutional affiliations.

Copyright: (C) 2021 by the authors Licensee MDPI, Basel, Switzerland. This article is an open access article distributed under the terms and conditions of the Creative Commons Attribution (CC BY) license (https:/ / creativecommons.org/licenses/by/ $4.0 /)$.
School of Sustainability, Arizona State University, Tempe, AZ 85281, USA; saelsaye@asu.edu (S.E.-S.); aopejin@asu.edu (A.O.)

* Correspondence: egiraud@asu.edu

Abstract: "Life, Liberty and Pursuit of Happiness", is what millions of Americans strive for. The onset of COVID-19 has highlighted the disparities that exist among Black, Indigenous and People of Color (BIPOC) communities, which are facing food access inequities. In this paper, we argue that engaging in growing food sustainably can improve food access, support food justice and enhance sense of purpose and well-being. We expand the notion of Food Well-Being (FWB) to include food producers-especially gardeners-and hypothesize that gardening has the potential to enhance FWB, regardless of the racial and socio-economic background. However, without policies tackling social and racial justice issues, structural barriers may hinder this potential. We use three studies to draw a rich profile of sustainable food gardeners in Arizona, USA and their well-being: (a) the children and teachers engaged in school gardens in the Phoenix metropolitan area; (b) sustainable gardeners and farmers in Phoenix and Tucson; (c) Arizona gardeners during the pandemic. The results show a connection between sustainable gardening and eudemonic well-being, and an impact on the five FWB dimensions (physical, intellectual, spiritual, emotional and social). However, without appropriate policies, funding and infrastructure, the impact might remain minimal, volatile and subject to tokenism.

Keywords: food well-being; food justice; sustainable gardening; Arizona; COVID-19; happiness

\section{Introduction}

The spread of COVID-19 across the United States in March 2020, outlined the risks and fragilities and inequities in food systems. The lockdowns and disruptions in food distribution and access highlighted the fragility of accessing basic goods, especially amongst more vulnerable communities, such as Black, Indigenous and People of Color (BIPOC) communities [1]. A research study conducted in the first 4 months of the pandemic in Arizona, found that $33 \%$ of 620 Arizona residents sampled were food insecure, with the Hispanic population being the highest hit [2]. Additionally, the pandemic had adverse effects on mental health, in particular due to reduced social interactions, increased economic uncertainty and health related concerns [2]. Concurrently, the pandemic situation also gave people both the time and the sense of urgency to garden more, which jointly provided opportunities for an increase in healthy food access. A surge of gardening activities around the globe has been documented during the lockdowns imposed by the COVID-19 pandemic [3,4], along with a growing interest in food self-reliance [5]. As an anecdotal evidence of this phenomenon: the number of subscribers to the Urban Farm newsletter in Arizona-a letter that focuses on home gardening and developing self-sufficient food production systems at home-has tripled with the start of the pandemic, going from 8000 new subscribers in a typical year, to 26,000 in 2020 [6]. Many individuals and communities around the world began focusing on strengthening their homegrown production, or even growing part of their food, finding solace in growing a garden and being part of nature [3]. Gardening activities-whether indoor or outdoor, and whether small, medium or large gardens-have been shown to contribute to greater health and well-being in individuals who partake in them $[7,8]$. 
Originally developed by Block et al. (2011), the food well-being (FWB) framework highlights the role of food to improve well-being for both individuals and society and uses a holistic approach to well-being (i.e., it includes for example spiritual and emotional dimensions in addition to nutritional health) $[9,10]$. However, this framework has largely been focused on food consumption activities, although a large body of literature shows the connection between growing food activities and well-being [3,7,11-13]. Additionally, a growing body of literature has shown a positive relationship between sustainability or sustainable development and well-being [14-20], especially how environmentally sustainable practices can help support ecosystems services which have direct impact on human well-being [21,22], but also how prosocial behaviors and connection to nature are key elements of sustainable practices and directly enhance human well-being [23,24]. More research has shown how sustainability can directly enhance eudemonic well-being [25], ranging from sustainable fisheries [26] to organizational psychology [27]. Yet, as far as we are aware, no research has shown the relationship between sustainable gardening and eudemonic well-being.

In this paper, we present three different case studies conducted in Arizona to assess how sustainable food growing practices (gardening and farming) can enhance well-beingand food well-being specifically. We also investigate the role of these activities to increase social justice and reduce food access discrepancies. We specifically ask two questions: (1) can growing your own food sustainably contribute to enhanced FWB and happinessnamely the eudemonic and hedonic aspects—especially during the COVID-19 pandemic? and (2) how can food gardening help mitigate food access inequalities, and social and racial injustice? To answer these questions, we delve into the literature and also focus on three studies conducted in Arizona: one on school gardens, one on small sustainable farmers and gardeners, and one on a sample of 96 gardeners.

\subsection{Food Well-Being Framework}

Taste and nutrition plays an important role in individual well-being. Nutrition has effects on growth, cell regeneration, and immunity among others, which are critical for human health [28-30] and well-being [31,32]. The sensory ability to taste also has a direct effect on well-being [33-35]. We saw for example that people who lost their sense of taste due to COVID reported emotional and psychological difficulties as a result [36]. The concept of food well-being (FWB) uses a holistic perspective to analyze the connection between people's relationship with food and their well-being. Frentz (2020) developed a framework that builds on the work of Block et.al 2011, and highlights the role of food to improve the well-being of both individual consumers and society as a whole. The premise is to enhance the discussion around people's relationship with food, and especially expand it beyond the biomedical model that traditionally focuses mainly on fulfilling nutritional needs. These needs are very important for human health and well-being, and a core component of the "physical dimension" in Frentz' framework described below. However, food well-being goes beyond. Frentz defines food well-being as "a multidimensional, synergetic construct represented on a continuum of a low to high relationship to food, taking into account hedonic (striving for positive emotions) and eudemonic (striving for a sense of fulfillment) approaches, where both subjective and objective evaluations of people's physical, emotional, social, intellectual, and spiritual relationship with food are taken into account [10] (p. 39)." Indeed, the framework assumes there are different elements that characterize food well-being. Firstly, FWB is set as a continuum, ranging from low to high, and can change throughout the individuals' life, based on an individual's experiences and external influences. It includes both hedonic and eudemonic approaches to well-being, consistently with part of the happiness literature $[13,37]$. Hedonic well-being refers to experiences of pleasure and associated with high positive emotions [37]. Eudemonic wellbeing is generally associated with long term fulfillment coming from a sense of purpose and actualizing one's full potential [37]. Secondly, it also assumes that there are five dimensions through which individuals evaluate their experiences with food: the physical 
dimension (which includes direct physical needs such as nutrition and sensory taste), the emotional dimension (such as the emotional experiences around food consumption), the social dimension (for example referring to culturally acceptable foods), the intellectual dimension (such as cognitive challenges associated with food), and the spiritual dimension associated for example with food religious practices and spiritual beliefs. Both subjective and objective evaluations of these experiences are recognized by the framework, in the forms of subjective individuals' perceptions of their own health and well-being or objective tests such as medical health assessments. Finally, food well-being is subject to external influences such as food availability, policies, literacy, socialization and marketing. Frentz represents food well-being as an individual journey in the form of a cycle, called food well-being cycle (FWBC), that we adjusted to focus on gardening (Figure 1).

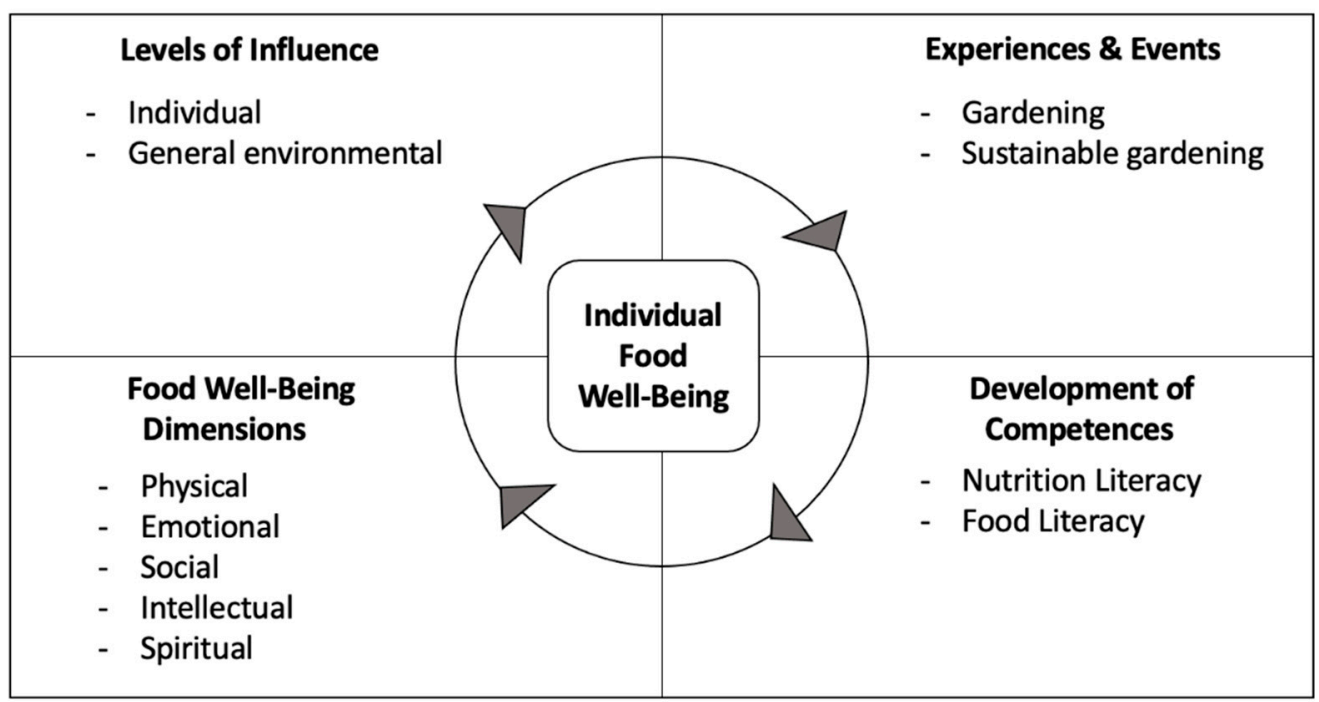

Figure 1. Gardening Food Well-being Cycle adjusted from Frentz' FWBC [10].

This paper focuses on a few of the aspects of the four components of the cycle, namely: a. two levels of influence (1) individuals demographic variables (such as age, race, gender and education level) and (2) general environmental influences (especially racial and social justice policies), b. food growing experiences, and c. the five FWB dimensions. We also integrate measures of hedonic and eudemonic well-being to our analysis. This cycle was applied to our understanding of how gardening in Arizona can ensure more happiness and tackle issues of racial disparity. Currently, the FWBC largely focuses on food consumption and explains its impact on individual well-being through that lens. Here, we focus on food growing practices, and use this cycle to understand whether and how they enhance well-being. One of the objectives of this paper is to expand the notion of food well-being to include food producers who play a critical role in this conversation.

\subsection{Gardening and Well-Being}

Previous research indicates that there is a strong connection between gardening and well-being. Studies have been conducted amongst people above 60 [38], school children [39,40], people with mental health [11], and leisure gardeners [8]. Some results indicate that gardening has positive impacts on mental health, reducing symptoms of depression and anxiety [11]. Some also linked gardening practices to an increased sense of connection to nature, or what is known as biophilia. Biophilia refers to human's innate affinity to life and life-like processes [41,42]. Researchers have suggested that this connection has helped people cope during the COVID-19 pandemic, as the reconnection to nature through gardening has lessened the impact of depression, apathy and has improved general well-being [3]. 
Research with elderly populations 60 years and above shows how gardening increases physical and mental activity and improves physical psychological well-being [38]. Research on school gardens emphasizes the increased popularity of using them to address curricula and learning outcomes [43], as well as promoting students' well-being through nature-reconnection $[38,44,45]$. Although there is not sufficient research on the long-term impacts of school gardens on children, research has shown that students experience positive emotions when they are outdoors, interacting with peers and educators, which positively impacts their self-esteem and allows them to develop empathy towards animals, insects and plants [44]. Furthermore, research shows that people who maintain a home-grown food culture also make better food choices in line with food well-being, such as sourcing locally, and sourcing fresh produce [46].

COVID-19 had a significant impact on people's well-being worldwide [3]. This was caused by different factors: loss of occupation, lack of access to affordable and healthy food and other goods, isolation and lack of connection to other people. As of April 2020 the increased unemployment rate had reached $13.2 \%$. This did eventually decline, however, Arizona continued to have high rates, such as 7.8\% in November 2020 [2]. Different studies [3,47] showcase that many people either started or increased their gardening practices during the COVID-19 shut-down. Gardening enabled people to have a bit of control on their food in a context of failing food chains, but it also appeared to alleviate their levels of stress [7]. People who gardened during the pandemic reported that it enabled them to distress and connect with nature when they were forced to shelter in place [3].

\subsection{Gardening for Social and Racial Justice}

Creating gardens in times of crises is not a new concept. Throughout US history gardens have surged in multiple instances. During the Great Depression, city governments supported the creation of welfare garden plots to combat hunger. Shortly after, during the World War 2, victory gardens gained traction to support the war effort. Recently, urban agriculture developed as a response to the 2008 economic crisis in cities such as Detroit. These are only a few historical examples but the agrarian history of this country is inextricably tied to the various inflows of populations who immigrated to the United States, bringing seeds and creating small-kitchen gardens to survive [48]. In Arizona, Chinese immigrants in the late 1800s started farming near Tucson, growing their own crops from cabbages to garlic and other fresh produce [49].

Although there is evidence that there are many benefits to community and urban gardens, such as improving health, generating income, building skills, enhancing community development and developing stronger community bonds [48], minorities are often confronted with the realities of land access and ownership, barriers imposed by the dominant model of industrial agriculture, discrimination and lack of time and resources to grow food. In the 1960s, Black independent farmers created Freedom Farms in the Deep South and in Detroit to counter racism and fight economic difficulties [50]. Unfortunately, they quickly dissolved by 1974 [50]. Today, African American farmers constitute only 1\% of all farmers in the United States. Food justice research highlights that both the industrial dominant and the more grassroot alternative food movements can perpetuate racial and social disparities in our food systems, and overall, different scholars argue that due to market tensions and state policies, race and class remain central to food justice issues [48,51].

However, new narratives are being written and new local systems are being created [51]. The alternative food movement often encourages the creation of community gardens with the intention of serving the community, especially in public space. Community gardens can often be spaces for cultivating social justice especially within cities and amongst disadvantaged communities, mostly communities of color [52]. When they are designed to do so, these spaces can help the communities resist neoliberalism and empower food producers and community leaders to have ownership over their food and fight food insecurity [53]. In these cases, the food growers are also activist citizens, fighting for the non-commodification of food [54]. It has been argued for several decades that urban 
agriculture can provide opportunities to improve food security, health, improve skills, provide jobs and even change food systems, however racial injustices and food disparities still remain $[48,51]$. Examples from marginalized communities across the globe use urban gardens as ways of reclaiming public space along with their food sovereignty $[48,52,55,56]$. However, there is often a toggling that takes place between what citizens want and have access to and what local governments and municipalities allow $[48,56]$. They often exist as both spaces building social, physical and environmental health, and spaces of conflict based on competing political, economic and ecological projects [57].

\subsection{Gardening in Arizona}

Arizona is growing to be one of the most diverse states in the USA. According to 2019 statistics from the census, Latinx represent $31.7 \%$ of the state's population. Arizona is also home to 22 official indigenous tribes and to a growing African Americans and Middle Eastern population. However, minorities lack representation in gardening. Farming and gardening in Maricopa County has been racialized since the 19th century. Still today, the majority of the food produced is not intended for local food security, but rather to make profit through crash crops [55]. Furthermore, Maricopa County is home to more than 4.8 million people and many members of minority groups live in one of the 55 documented food deserts [43,58], defined as an area without access to fresh, healthy and affordable food, where at least one-third of the population live more than a mile from a supermarket [59]. Unfortunately, urban gardens and farmers are rarely connected to food desert sites [60], and there are multiple land access issues. Agricultural land is being given to developers, and few accessible zoning permits exist to facilitate farming and gardening [55]. Little research has been conducted on the relationship between gardening, well-being and justice in Arizona. The few that exist argue that although there is a move towards urban gardens with increasingly supportive policies, not much work has been invested in ensuring social justice and tackling fair food access for diverse communities [55]. There is indeed a growing population of gardeners amongst minority groups, and this increased during the pandemic, but many obstacles hinder their growth, from justice issues to the challenges of a rough arid climate.

Due to difficult climate conditions, maintaining gardens in Arizona is a real struggle, be it for school gardens with few expert teachers and resources, for small-to-medium scale farmers who have land tenure and certification challenges, or even home-gardeners who are battling heat and low soil fertility. Although the recent increase in master gardeners trained through a program led by the University of Arizona [55] has helped spreading desert gardening knowledge, the limiting factors of growing in an arid region are still a reality. For farms and some areas of the city, water comes from the Salt River Project (SRP) and allows cheap food irrigation. For others, they need to use tap water at much higher prices. Additionally, soils are not very fertile and a lot of soil amendments are needed to ensure soil productivity. To successfully grow in an arid environment, a gardener needs water management and harvesting skills, soil health knowledge, and the ability to select drought-tolerant seeds and seedlings among others. Despite these challenges, urban gardens are on the rise and have especially multiplied during the pandemic.

\section{Materials and Methods}

To assess the relationship between gardening (in particular sustainable gardening), food well-being, and food justice, we conducted three small studies that build on each other and examine these variables. The three studies give an overview across three types of gardening as they relate to Arizona. The first study was conducted in 2018, and consists of 21 semi-directed interviews of school teachers from nine elementary schools in the greater Phoenix area. It focuses on the relationship between gardening and experienced well-being across the five dimensions of FWB. The second study, conducted in 2020-2021, includes interviews of sustainable small-scale farmers and gardeners in Phoenix and Tucson, the two biggest cities in Arizona. This study focuses on sustainable growing practices specifically, 
and how they relate to the FWB framework. Conducted in Spring 2021, the third study is an online survey of 96 self-identified gardeners in Arizona. For this study, we build on study 2 to develop a Sustainable Gardening Score (SGS) and relate it to existing measures of wellbeing from the literature. The pandemic affected the design of our studies 2 and 3: most interviews were conducted online or 6 feet apart, and the survey recruitment, completion and compensation occurred $100 \%$ online.

\subsection{Study 1}

In 2018, the authors of this paper and a group of graduate students from Arizona State University conducted a research project on school gardens in the Phoenix metropolitan area as part of a class in Food System Sustainability. The original goal of the project was to assess the opportunities and challenges faced by the school teachers in using and maintaining school gardens, and a total of 21 teachers working in nine different schools were interviewed for an average of $20 \mathrm{~min}$. For example, we asked teachers about what they initially hoped to achieve using school gardens, and the benefits of using the garden for the students, the teachers, and the school community. We also asked them about the specific challenges they faced with the school gardens, and the strategies to overcome them. The answers pointed to the relationship between gardening activities and enhanced well-being among teachers and students. We transcribed the interviews and coded the transcripts using the food well-being framework-in particular, the 5 dimensions: physical, emotional, social, intellectual and spiritual, and the "general environmental influences" — to gain a preliminary understanding of how gardening experiences can be part of the food well-being cycle. For our analysis, we use a pre-existing conceptual model (the FWBC framework) that we enhance using inductive strategies [61] (p. 335) to determine (1) how gardening activities affect well-being and especially the five FWB dimensions, and (2) what are the specific general environment influences that can have an effect on these relationships.

\subsection{Study 2}

Building on the results from study 1, we conducted 13 semi-structured interviews with small farmers and gardeners using sustainable growing techniques. The interviews took place between 2020 and 2021. The interviews were semi directed and included open ended questions such as "can you tell us the journey of how you became a gardener/farmer?", "what does growing sustainably mean to you?", "what are your motivations and challenges to garden/farm?", "can you give us examples of experiences related to gardening/farming that you find particularly enjoyable?". One of the interviews was conducted over email, and the others were conducted in person 6 feet apart, by phone, or over zoom. They were recorded, transcribed and uploaded onto MAXQDA, where we subsequently coded them based on previous literature and in-vivo (Table 1). Specifically, the codes used were wellbeing (especially hedonic, eudemonic, and the five dimensions from the FWB framework), racial and social justice, and sustainable gardening. The codes then helped us understand how the gardeners and farmers define sustainable growing practices, and the relationship between these practices and their overall well-being. We used the same method of analysis as in Study 1, with a focus on sustainable growing activities. 
Table 1. Codebook.

\begin{tabular}{|c|c|c|}
\hline Code Name & Definition & Source \\
\hline Hedonic WB & Well-being associated with a sense of pleasure and positive emotions [37]. & Deci and Ryan, 2008 \\
\hline Eudemonic WB & Well-being associated with sense of fulfillment and purpose in life [37]. & Deci and Ryan, 2008 \\
\hline Physical dimension (FWB) & $\begin{array}{l}\text { Well-being as it relates to body awareness, healthy dietary choices and } \\
\text { eating habits [10]. }\end{array}$ & Frentz, 2020 \\
\hline $\begin{array}{l}\text { Emotional dimension } \\
\qquad(\text { FWB })\end{array}$ & $\begin{array}{l}\text { Well-being in relation to someone's emotional state and how they cope } \\
\text { with stressors. Experiencing, expressing, and dealing with emotions that } \\
\text { are associated with food-related activities [10]. }\end{array}$ & Frentz, 2020 \\
\hline $\begin{array}{l}\text { Intellectual dimension } \\
\qquad(\text { FWB })\end{array}$ & $\begin{array}{l}\text { Well-being as it stimulates the mind, and thinking and being intellectually } \\
\text { engaged [10]. } \\
\begin{array}{c}\text { Ex: a hobby (fitting for gardening), intellectual stimulation of gardening in } \\
\text { a desert climate because it is so difficult }\end{array}\end{array}$ & Frentz, 2020 \\
\hline Social dimension (FWB) & $\begin{array}{l}\text { Wellbeing in relation to social interactions. May include norms, values, } \\
\text { status symbol, and traditions and how these affect food-related behaviors } \\
\text { (ex: what to grow, what to eat, how to grow) [10]. }\end{array}$ & Frentz, 2020 \\
\hline Spiritual dimension (FWB) & $\begin{array}{l}\text { Well-being in relation to spirituality and one's overall worldview. } \\
\text { Harmony with religious views, feeling at peace with oneself, support } \\
\text { mind-body connection [10]. }\end{array}$ & Frentz, 2020 \\
\hline Racial and social justice & $\begin{array}{l}\text { A socially just food system is one in which power and material resources } \\
\text { are shared equitably so that people and communities (regardless of race or } \\
\text { social status) can meet their needs, and live with security and dignity, now } \\
\text { and into the future [62]. }\end{array}$ & Allen, 2010 \\
\hline Sustainable gardening & $\begin{array}{l}\text { References to methods of food production, descriptions of what it means to } \\
\text { them to grow food sustainably. }\end{array}$ & in-vivo \\
\hline
\end{tabular}

\subsection{Study 3}

Using our analysis from sustainable growing practices in study 2, we developed a Sustainable Gardening Score (SGS) (Table 2) and conducted a survey to analyze the relationship between sustainable growing practices and well-being in a bigger sample. In order to test the hypothesis that sustainable gardening enhances eudemonic well-being, and sense of purpose, we also asked participants about their eudemonic well-being, and if they believed that their backyard contributed to biodiversity at home (Purpose 1) or around the world (Purpose 2) [63]. Other variables included the barriers experienced by the participants to garden or to garden more, changes in gardening pattern during the COVID-19 pandemic, race, age and education level. We conducted a series of linear regressions to determine the predictors of the participants' eudemonic well-being and sense of purpose (Purpose 1 and Purpose 2), and test the hypothesis that sustainable gardening enhances eudemonic well-being and sense of purpose. The survey was conducted on Qualtrics and was distributed through three local networks: two which focus on sustainable gardening and farming education in Arizona (the Urban Farm and the Rocky Mountain Seed Alliance), and one that tackles issues of racial justice (Phoenix Black Lives Matters). In total, 96 participants self-identified as gardeners and took the survey. In our sample, 76 respondents were over the age of $45(79 \%)$ and 39 had a graduate degree $(41 \%)$. On race, 75 participants identified as Caucasians (78\%), nine identified as Afro-American (9\%), three as Hispanics ( $3 \%)$, one as Asian, three as others, four preferred not to disclose this information, and one did not answer. 
Table 2. Sustainable Gardening Score (SGS).

\begin{tabular}{|c|c|}
\hline Question Items & Scale \\
\hline $\begin{array}{l}\text { 1. Do you use synthetic pesticides and/or fertilizers for your } \\
\text { outside spaces? }\end{array}$ & $\begin{array}{l}\text { 1: yes, pesticides and fertilizers, 2: only pesticides, 3: only } \\
\text { fertilizers, } 4 \text { : none }\end{array}$ \\
\hline 2. Do you use mulch? & 1: yes, 2: no \\
\hline 3. What type of irrigation do you use? & $\begin{array}{c}\text { 1: drip irrigation, 2: sub-surface irrigation, 3: flood irrigation, } \\
\text { 4: hose, 5: sprinklers, 6: others }\end{array}$ \\
\hline 4. What time of the day do you water your garden? & $\begin{array}{l}\text { 1: morning, 2: day time (10 to 4), 3: evening, 4: whenever I } \\
\text { have time }\end{array}$ \\
\hline 5. Do you use compost? & $1:$ yes, $2:$ no \\
\hline 6. Do you use your own organic waste to make compost? & 1: yes, 2: no \\
\hline 7. What type of seeds do you use? & $\begin{array}{l}\text { 1: organic, 2: local, 3: swapped seeds, 4: saved seeds, } \\
\text { 5: non-organic seeds, 6: GMO seeds }\end{array}$ \\
\hline $\begin{array}{l}\text { 8. Which of the following actions do you take to provide for the } \\
\text { native wildlife in and around your garden? [63] }\end{array}$ & $\begin{array}{l}\text { 1: I make sure there are flowers, } 2 \text { : I try to attract species that } \\
\text { naturally keep pests out, } 3 \text { : I leave some leaves, branches and } \\
\text { others, 4: I have a water pond, } 5: \text { my garden is surrounded by } \\
\text { natural hedges, } 6 \text { : I don't do anything special }\end{array}$ \\
\hline
\end{tabular}

\section{Results}

\subsection{Study 1}

Although not a food consumption activity, gardening falls under the "experience and events" phase of the food well-being cycle. It enables students and teachers to have access to first hand food growing experiences that can enhance both nutrition and food literacy. For example, students can learn about the vitamins, water and carbohydrates that compose the produce that they help to grow, which improves their ability to understand nutrition information (nutrition literacy). Additionally, they are able to bring fresh vegetables home, where they can wash, prepare and cook the produce, and assess the quantities needed for their families (food literacy). These experiences give them new perspectives on food, which in turn creates enhanced lifestyle choices, and positively affects their well-being.

Our results are consistent with the literature $[39,57]$ and show a positive relationship between maintaining school gardens and wellbeing for both children and teachers. More specifically, the results show an effect on most of the food well-being dimensions. Results also illustrate the influences of what Frentz calls "general environment [10] (p. 50)" on the food well-being cycle, especially in the forms of barriers to successful gardening programs.

\subsubsection{Food Well-Being Dimensions}

Many of the interviewed teachers mentioned various benefits to students. The interviews were coded against the five dimensions of the FWB framework. Intellectual and physical well-being were the most prevalent, and to a lesser extent social and emotional well-being. There was no mention of spiritual well-being.

- Intellectual well-being. Six out of the nine schools saw a value in intellectual wellbeing, the garden enabled teachers to make linkages to science, social studies and math curricula, and they were able to have students truly understand where their food comes from and how it grows. A Broadmor elementary school teacher said "The garden helps relate text to real world and real world to text-spelling, vocabulary, and the science curriculum supports the garden, math, social studies." In a different school, a teacher emphasized the potentials of the garden to teach problem solving skills: "I really appreciated the fact that I think our kids can "problem solve", so if perhaps they planted something and it is not growing, let's try to problem solve why is it or why other plants are growing and ours aren't."

- Physical well-being. Six out of nine schools saw an effect on physical well-being. Gardening allowed students to be physically active outside in the garden, and it 
allowed them to consume fresh produce directly from the garden. "They might not have ever tasted an eggplant or something else before, and to realize that they liked it... so it really opened up their eyes to healthy food" (Echo Canyon elementary teacher).

- Social well-being. Teachers also mentioned how the garden helped build a sense of community for children and parents, and increased social well-being. Indeed, gardening helped children work together in an informal setting, and enabled them to connect gardening practices to larger sustainability and social issues. "(Gardening is) great for socialization for my kids" (Echo Canyon elementary teacher). Gardening also enhances teachers' social well-being by a. giving alternative learning opportunities to children who do not perform well in traditional classroom environments; $b$. involving and accessing parents, community members and other departments in the school; $c$. building relationships with children who are less social in class.

- Emotional well-being. Gardening allowed students to develop a sense of care and empathy for each other, and nature, as well as create a sense of calm and peacefulness which can be described as emotional well-being. When asked about the benefits of the school garden, a Madison Rose Lane teacher said "I think just the overall feel of being surrounded by the garden, being in nature, building respect for nature and for caring."

- Spiritual well-being. The spiritual component was not mentioned in any of the interviews. We believe that it might be difficult for teachers to connect spiritually with students given the diversity of their backgrounds, and because public schools are not traditionally spaces of discussions around spiritual beliefs.

\subsubsection{General Environmental Influences}

We found that various levels of policies had a direct effect on the potential of gardening activities to enhance well-being. For example, gardens who benefitted from the experience and involvement of a master gardener or a highly knowledgeable school teacher were the most successful. In these cases, gardens produced food for students to share. They were able to enhance food and nutrition literacy through experiential learning, participated in improving food socialization, and contributed to well-being. Unfortunately, teachers' education usually does not include significant training in gardening skills, which are not considered to be a critical part of curriculums. Only a handful of schools had access to master gardeners to ensure the availability of food and a continuous production through growing seeds and seedlings. In schools that lacked funding, internal policies and community support to strengthen the gardening program, the garden played a very minor role in students and teachers' life at school. "The garden activity is not part of our programming, so little time is available" (Solano elementary teacher).

These results show that gardening is a relevant experience for the food-well-being cycle, as it holds the potential to increase both teachers and children's well-being and to provide fresh food access for the communities they serve. However, without the proper general environmental influences, issues of internal policies, teachers' training, funding and infrastructures around the garden can become barriers to this potential. This study encouraged us to dig deeper into the relationship between gardening and happiness in terms of eudemonic and hedonic well-being, as well as discover whether it can tackle disparities found in food access.

\subsection{Study 2}

Building on our results from the school garden study, we sought to examine if the relationship between growing food activities and well-being could also be observed for adult populations, and especially for those who grow food for a living (farmers) and if their well-being differs from those who grow food as a leisure (gardeners). Among the interview participants, seven people identified as farmers and six identified as gardeners. Two of them were African American, one was Latinx and the rest were Caucasian, from both Phoenix and Tucson metropolitan areas. For members of a minority group, the questions of 
racial and social justice and their impacts on their activity were brought up quickly during the interview.

Additionally, we specifically chose to interview growers who use environmentally sustainable practices, to assess the relationship between sustainable gardening practices. None of them used synthetic pesticides or fertilizers, and 6 of them used permaculture principles and techniques [64]. As we conducted the interviews between 2020 and 2021, many interviewees referred to the COVID-19 pandemic, and how that affected their relationship to gardening and farming. For example, a Phoenix community gardener who sells some of her produce discussed the adjustments she made to respect measures of social distancing: "I put a cooler at my front door and you know message them and say your stuff's here. This is how much you owe me. They come to the front door, take it out the cooler, leave the money and off they go. So there's absolutely no involvement of any viral transfer." Although it required adjustments, the pandemic did not seem to transform the positive relationship between growing food and well-being in our sample.

\subsubsection{Sustainable Gardening}

Sustainable farming was defined by the farmers as multifold, and we coded the components which were redundant across multiple interviews. The six most important elements were rainwater harvesting and water-saving irrigation techniques, adaptation to heat and local climate, seed saving and sharing, soil and plant health enhancing practices such as mulching, composting, and the absence of synthetic pesticides and fertilizers. We conducted a lexical analysis of these components of sustainable farming and gardening practices to assess their frequency across our interviews (Table 3).

Table 3. Lexical analysis of sustainable gardening components.

\begin{tabular}{|c|c|c|}
\hline Component & $\begin{array}{l}\text { Number of } \\
\text { Interviews }\end{array}$ & Quote Example \\
\hline $\begin{array}{l}\text { Rainwater harvesting, water saving } \\
\text { irrigation systems }\end{array}$ & 11 & $\begin{array}{c}\text { "Around trees, we have a swale, it's used for rainwater } \\
\text { harvesting [...] for the drier climates" }\end{array}$ \\
\hline $\begin{array}{l}\text { Adaptation to climate and } \\
\text { bioregion (heat, climate, weather) }\end{array}$ & 10 & $\begin{array}{l}\text { "[The chickens] are adapted to being in the heat and more } \\
\text { resilient. [...] So that's a little story from resilience and adaptation } \\
\text { and how, yes, we can begin to adapt our seeds, our animals and } \\
\text { ourselves to higher heat." }\end{array}$ \\
\hline Mulch, mulching & 5 & $\begin{array}{c}\text { "So under our shades with our mulch, the quality of our soil, the } \\
\text { temperature in our gardens is } 10 \text { degrees cooler" }\end{array}$ \\
\hline Seed saving, self-seeding plants & 4 & $\begin{array}{c}\text { "We try to save some seeds and this year we got a few seeds from } \\
\text { the seed library" }\end{array}$ \\
\hline Composting & 9 & $\begin{array}{l}\text { "(there are various) resources that I can harvest from the garden, } \\
\text { whether it's pine needles to put in the compost or vegetables to } \\
\text { bring in the kitchen, and the scraps go back out to the compost, } \\
\text { which is the classic example of compost to veggie garden to } \\
\text { kitchen back to the compost again" }\end{array}$ \\
\hline $\begin{array}{l}\text { No chemicals (pesticides } \\
\text { and fertilizers) }\end{array}$ & 6 & $\begin{array}{l}\text { "When you put pesticides and insecticides and all kinds of } \\
\text { chemicals in the farming system that's how you destroy" }\end{array}$ \\
\hline
\end{tabular}

\subsubsection{Well-Being}

To analyze the references to well-being, we first looked at the references to eudemonic and hedonic well-being, and then conducted a more detailed analysis of the five dimensions of the FWB framework. We did not find differences between the farmers and gardeners who participated in our interviews, and both groups had similar results.

Eudemonic well-being was highlighted by 11 interviewees, especially as it relates to the sense of purpose experienced by farmers and gardeners. They talked about how meaningful growing food is to them. After detailing her life experience in agriculture, 
a Phoenix farmer summarized: "food is a big issue for me. It's not just a little one." Similarly, a Tucson gardener described gardening as "something very meaningful and essential" to her. "This is really wonderful" she added. The well-being derived from a sense of purpose was also heightened by the pleasure derived from the commitment to a cause bigger than themselves. A Phoenician farmer explained: “My objective is to demonstrate first to my family and then to my community that it's possible to live life on the Earth and still have the things that you want to have." In the same vein, a Tucson community gardener told us: "I feel like growing your own food is a revolutionary act (...) Growing the food is an excuse you know, it is like the vehicle that takes people to like a larger accomplishment." Self-sufficiency and supporting the health of their communities were particularly strong motives. Indeed, farmers and gardeners alike identified the motivation to be resilient and become self-sufficient (both individually and as a community), which was particularly relevant during the early days of the pandemic when food shortages in supermarkets encouraged an increased reliance on smaller scale and local productions. Farmers and gardeners alike also stated that their work contributed to the health of their community, especially as a means to educate about healthier choices.

At the same time, the participants often highlighted the hedonic challenges (physical and sometimes emotional) associated with farming and gardening in the Arizona climate. Indeed, as mentioned above, farming in Arizona, comes with many challenges, especially for those who are trying to farm sustainably as it often implies an increased use of manpower. For example, a farmer insisted how hard it has become to farm in Phoenix: "All I know is now and it is getting hotter and harder. The pests are not getting laid to sleep and going dormant during the winter months. The pest pressure is on us all the time. The weed pressure, same thing." Yet, in the midst of these challenges, the strong sense of purpose seemed to participate in helping them to overcome these difficulties: "I'm very connected to the Earth and it tends to empower me to continue to do what I do. Like, (...) it's one hundred and thirteen degrees at twelve thirty in the afternoon and I'm like, "oh my gosh, I have to quit right now. I can't do this anymore. This is crazy." And it's like "oh all I need is two more bunches, just keep pushing. You're not going to die in five minutes, OK?" I mean, this is me talking to myself in the heat, on the field, and I'm by myself out there and it's hot and it's hard. (...) And all of a sudden when it's so hot, I think I can't make it anymore, a cool breeze. The sweat on my body comes and even at one hundred and thirteen degrees, that cool breeze after you're sweating is just enough of nature to keep you moving forward." (Phoenix farmer).

\subsubsection{Food Well-Being Dimensions}

To get a more detailed picture of the participants' well-being, we also coded their interview responses across the 5 FWB dimensions (Table 4). The physical dimension appeared the most often because the majority of participants referred to the pleasure of producing and eating healthy fresh food. The social dimension was also mentioned frequently, which is consistent with the sense of purpose and contribution to communities that we discussed earlier. The spiritual dimension, largely characterized by a deep sense of connection with nature, also adds another layer of understanding to the eudemonic well-being experienced when growing food.

In order to identify the dimensions of FWB that were discussed closely to sustainable gardening descriptions, we mapped the codes to analyze their proximity in the transcripts with a maximum distance of five paragraphs (Figure 2). In our sample, sustainable gardening practices had the highest proximity with the social and spiritual dimensions, although these were not the most frequently mentioned. This means that in the interviews, when participants referred to the social and/or spiritual dimensions well-being they derive from growing food, they did so shortly after or before describing their sustainable food growing practices. For example, participants mentioned the sacred relationship that occurs between them and their plants while tending to them. "The act of caring for a plant and receiving nourishment from it is a sacred reciprocal act, where you feel the relationship with nature physically 
in your body, via the food you eat" (Tucson gardener). Not all participants expressed social and spiritual well-being, but when they did, it was interconnected with their definitions of growing sustainably.

Table 4. Frequencies of Food Well-being dimensions across interviews.

\begin{tabular}{cccccc}
\hline & Spiritual & Intellectual & Social & Emotional & Physical \\
\hline \#1 Phoenix farmer & 3 & 0 & 1 & 3 & 4 \\
\#2 Phoenix farmer & 1 & 0 & 1 & 0 & 2 \\
\#3 Phoenix farmer & 1 & 1 & 3 & 2 & 3 \\
\#4 Phoenix farmer & 1 & 5 & 0 & 1 & 1 \\
\#5 Phoenix farmer & 3 & 1 & 5 & 1 & 3 \\
\#6 Phoenix farmer & 0 & 3 & 0 & 0 & 1 \\
\#7 Phoenix gardener & 5 & 2 & 1 & 3 & 2 \\
\#8 Phoenix gardener & 2 & 1 & 4 & 3 & 9 \\
\#9 Phoenix gardener & 0 & 0 & 1 & 3 & 0 \\
\#10 Tucson gardener & 0 & 0 & 5 & 0 & 0 \\
\#11 Tucson farmer & 0 & 0 & 0 & 1 & 1 \\
\#12 Tucson gardener & 0 & 0 & 2 & 1 & 2 \\
\#13 Tucson gardener & 2 & 0 & 0 & 0 & 0 \\
Total & 18 & 13 & 23 & 18 & 28 \\
\hline
\end{tabular}

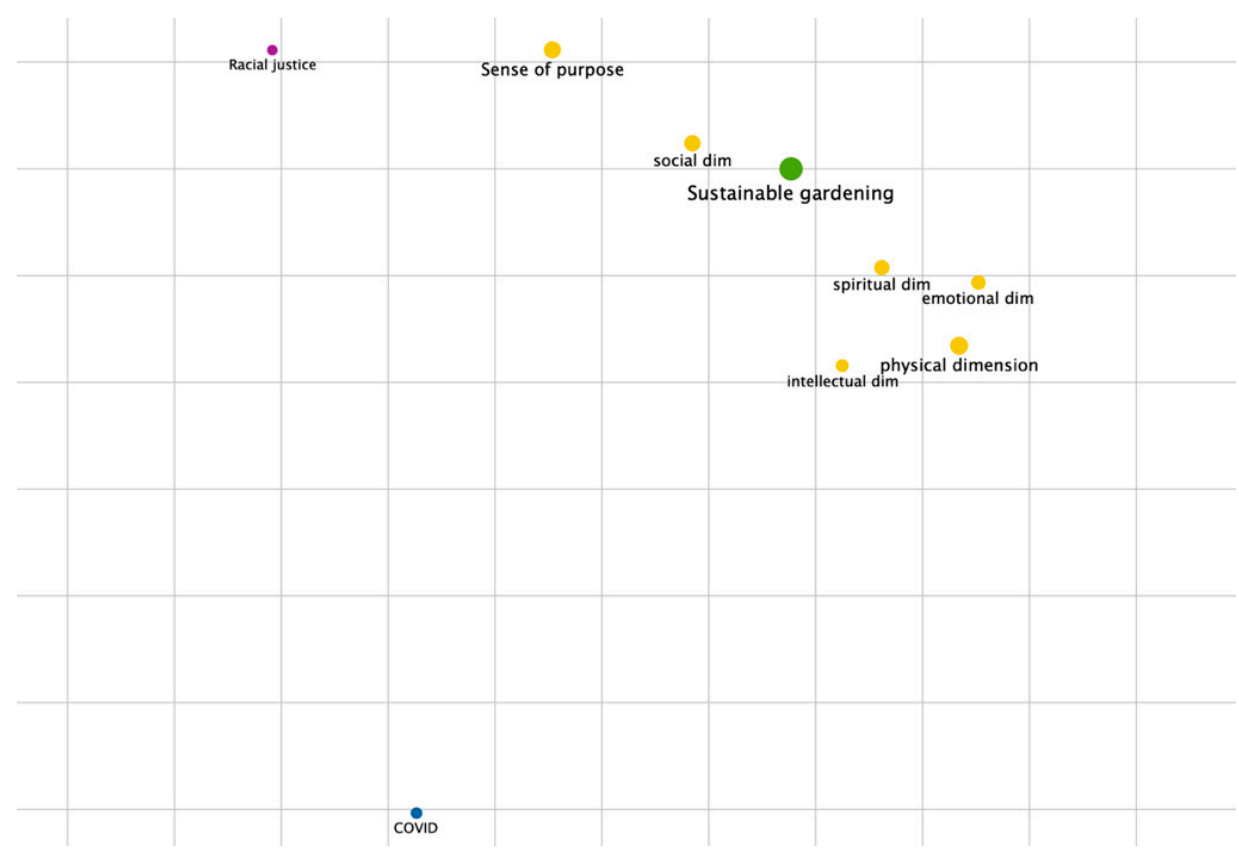

Figure 2. Map of the interview codes developed using MAXQDA. In our transcription of the interviews, the references to sustainable food growing practices occurred within a 5 paragraph distance from references to (1) the social, (2) the spiritual, (3) the emotional, (4) the intellectual and (5) the physical dimension of well-being participants derive from growing food, ranked from highest to lowest proximity.

\subsubsection{Social and Racial Justice in the General Environment}

Most farmers were outspoken about the issues in our food system, and about the policies and larger cultural values that hampered their capacity to do their work and could be experienced as a form of social discrimination. One Phoenix farmer described the farming land access difficulties coming from zoning issues and the constant work to be heard: "I think there's a lot of talk out there about it, really, but without actualizing and saving farmland or open spaces from development, it's not going to happen. And so that becomes a citywide urban and zoning issue, which needs constant voices saying 'no more houses don't develop that 
space, we need that open space, we need those lands for food production.'" Another farmer talked about a general cultural lack of respect towards farmers "I would love for the growers of food to be as respected, if not even possibly more, than the doctors. Now, on the socioeconomic of it all, I don't know if that's possible, because right now a doctor on the socioeconomic level is paid so much more and can buy respect much easier than a farmer. And that's pretty evident. (...) You and I could dress like a really wealthy person. And I would say I'm treated differently than when I'm dressed like a farmer. I just am."

In total, 3 of the 13 farmers were from a minority group, and all three emphasized the critical dimension of community engagement. Their work centered on issues of racial and social justice, either by working on issues of food insecurity or poverty within their communities or by providing a form of professional training to their members. They described how the "general environment" is not fair for some of their community members, and how their work seeks to create solutions. One LatinX community gardener stated "We're moving south of the border, creating a series of trainings, because we cannot ignore the fact that a lot of the food that we get here comes from there so... We need to make sure that the practices and the way people are treated is fair." A Black farmer talked about the "prison pipeline" in his community and how it "takes the youth away". He highlighted that his work with the garden served as prevention and rehabilitation for people to "grow roots" and transform their lives. Non-minority farmers and gardeners also sought to create solutions to negative "general environmental influences" in our food system. However, they often were able to focus less on racial justice issues. Instead, they concentrated mostly on reducing environmental harm, and on some dimensions of social justice such as growing healthy affordable organic food for their communities, and educating people to grow on their own. Minority farmers and gardeners too worked on reducing environmental harm, growing healthy food, and educating their communities. In addition to this work, they also sought to tackle racial injustice because they could not "ignore the fact".

\subsection{Study 3}

The first objective of this study was to test the relationship between gardening and wellbeing during the COVID-19 pandemic on a larger sample, and especially the hypothesis that gardening sustainably enhances eudemonic well-being using a series of linear regression between measures of eudemonic well-being and sense of environmental purpose, and a Sustainable Gardening Score (SGS). Second, the study also sought to identify the barriers to gardening experienced by the participants, and how they relate to "general environmental influences" from Frentz' framework [10].

Gardening practices appeared to support many of the respondents during COVID-19. In total, 54\% declared that gardening activities increased during COVID-19, and many also stated that gardening helped them reduce food expenses and access food when it was a challenge, which contributed to their well-being. Based on our lexical analysis of sustainable gardening in Study 2, we first developed a Sustainable Gardening Score (SGS) including the 6 components listed in Table 3. An individual score was calculated for each survey participant based on their answers to a set of 8 questions (Table 2). We scaled the range of possible answers and attributed a number of points to participants for each question, for example, 2 points if they used mulch, 0 points if they did not. We added their number of points per question and divided the result by the total number of possible points. The resulting SGS ranges between 0 and 1. Second, we ran three sets of linear regression to observe the relationship between eudemonic well-being and our SGS (Table 5). To measure eudemonic well-being, we used the six question items from the Pemberton Happiness Scale (Section A) that focus on eudemonic well-being [65], for example: "gardening makes me feel a sense of purpose and fulfillment" ( 1 = completely disagree, 5 = completely agree). In order to clarify the sense of purpose associated with sustainable gardening, we also asked the participants if they believe their gardens contribute to nature close to their home (Purpose 1) and to global biodiversity (Purpose 2), using a reverse scoring scale [63]. Our results show that the SGS is a significant predictor of eudemonic well-being and of sense of 
purpose as it relates to the impacts of gardening on the natural environment. Although the adjusted $R^{2}$ is quite small in each of the regression, and only a small percentage of the variance in our dependent variables can be explained by our statistical model (7-20\%), it appears that people who adopted more sustainable gardening practices were more likely to report higher eudemonic well-being, and to believe their garden had an environmental purpose, which confirmed our hypothesis.

Table 5. Linear regressions of Eudemonic Well-being and Purpose 1 and 2 on SGS, Age, Education, Race and Data sample $(n=96)$.

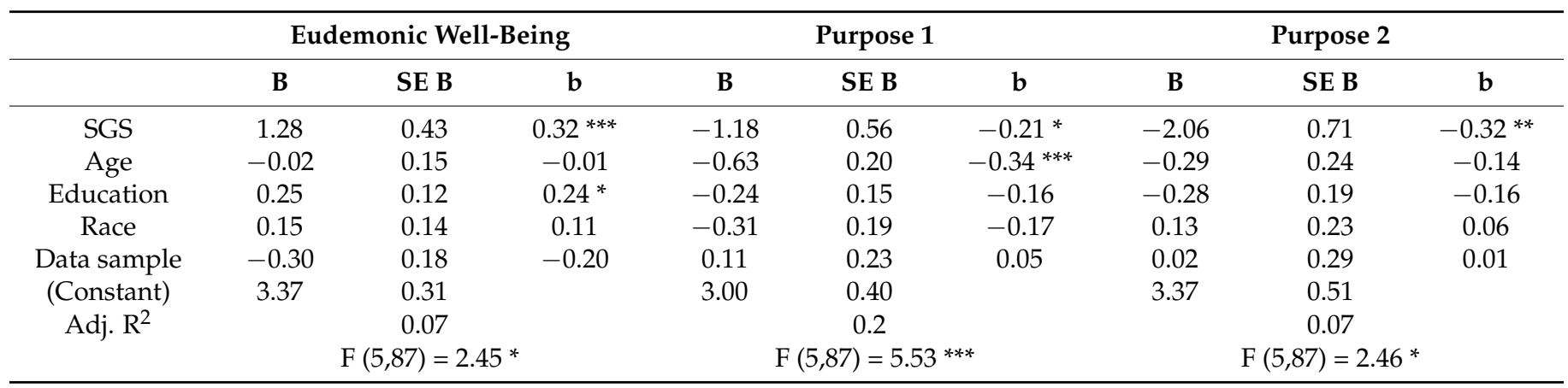

${ }^{* * *} p$-value $\leq 0.001,{ }^{* *} p$-value $\leq 0.01,{ }^{*} p$-value $\leq 0.05$

To identify the "general environmental influences" to gardening in our sample, we also asked survey participants about the barriers they faced in their attempt to garden or to garden more. We adjusted the questions items from a survey on food access and affordability conducted by Missoula Food Security Initiative [66] to specifically focus on gardening. In our sample, race, education and age were not significantly correlated to any of the barriers identified by the respondents. The top answer came from a third of our respondents who said they didn't have enough knowledge. Second and third top answers related to lack of time (30\%) and lack of space respectively (28\%) (Figure 3). Respondents also mentioned the financial cost of gardening and having a physical disability as a barrier. These barriers highlight a lack of accessibility in gardening activities, and how it relates to larger environmental constraints. Beyond individual choices, the lack of knowledge, time, space and money point to larger societal issues.

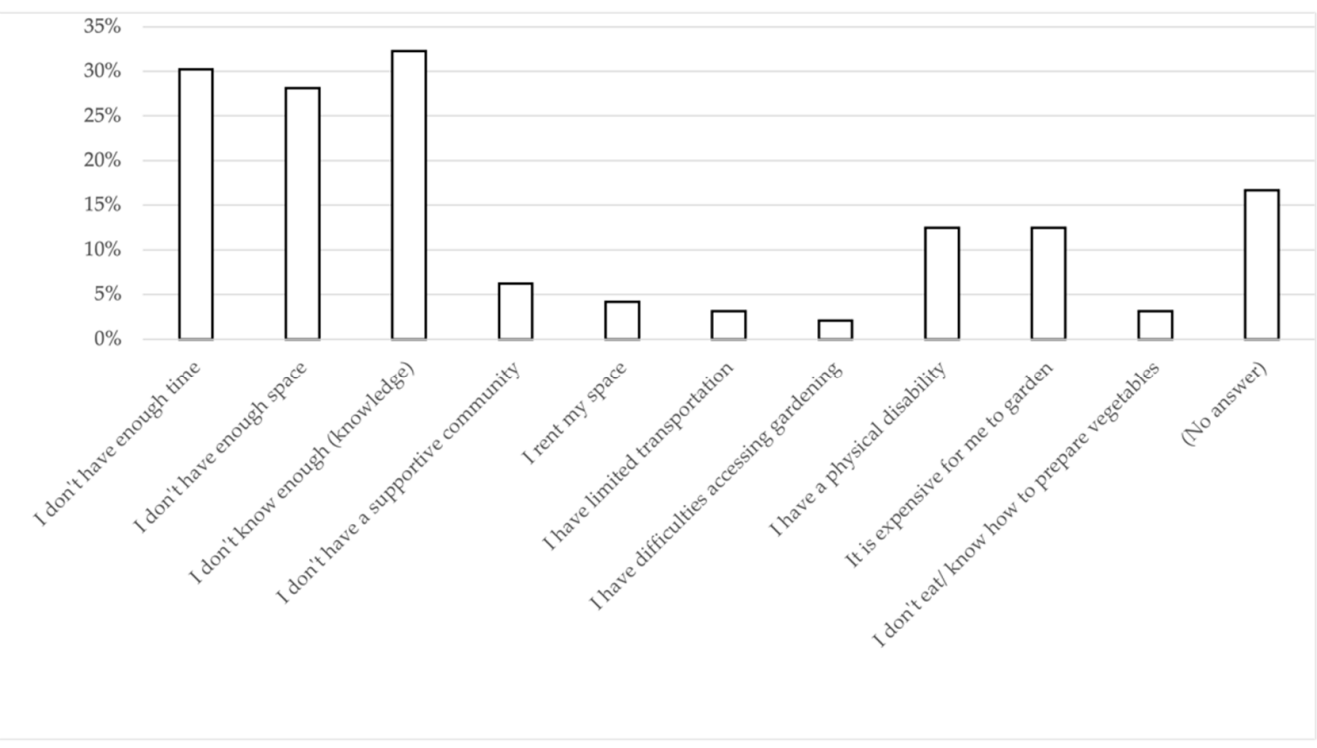

Figure 3. Barriers to gardening. Question: “Which of the following barriers apply to you to garden or to garden more? (select all that apply)" $(n=96)$. 


\section{Discussion}

Across our studies, gardening appeared to have a positive impact on Food Well-Being and happiness. For school children, gardening was associated with hedonic well-being, as they experienced the pleasures of being outdoors, tasting fresh fruits and vegetables, and interacting with peers and teachers in a more informal setting than the traditional classroom. Hedonic well-being was also expressed by participants in our second and third study, along the same lines as school children: tastiness of fresh food, pleasure of being outside and agreeable time spent with others. Eudemonic well-being was also reported in our three studies. Teachers explained how gardening with the children heightened their sense of purpose. Study 2 participants also highlighted how producing food is deeply meaningful to them, especially as it gives them the opportunity to be more self-sufficient and a purpose in having a positive impact on their communities and the environment. This sense of purpose was powerful enough to compensate the hedonic challenges of growing good in difficult environmental and social conditions. Additionally, we found in our third study that Arizona gardeners who use more sustainable growing practices were likely to also report higher purpose and eudemonic well-being. To our knowledge, no other study has shown a relationship between sustainable gardening and eudemonic well-being.

In study 1 and 2, this paper also analyzed the relationship between gardening and the five dimensions of FWB. Conceptually, physical well-being largely intersects with hedonic well-being, and it was reported as the most prevalent dimension in both studies. This is consistent with the gardening literature which has long identified the health benefits of gardening $[67,68]$ and how they contribute to general well-being $[8,11,38,39]$. In addition, both the social and emotional dimensions appeared in most interviews in study 1 and 2 . Interestingly, the intellectual dimension which appeared in most interviews with teachers was also the dimension least mentioned by sustainable farmers. Inversely, the spiritual dimension was never mentioned by school teachers while it appeared in 8 out of 13 interviews in our second study. In study 3 , we did not specifically test the relationship between gardening and the five dimensions of the FWB framework, and this could be the focus of further research. Indeed, the development of instruments that would specifically test for these dimensions might help to better identify the nuances across them in a larger sample.

In her research, Frentz describes the influences of the general environment as those exerted by governments, public institutions and non-profit organizations that shape the consumers' physical surroundings by implementing policies [10]. The structural causes of racial and social inequality lay in these influences. Across our studies, gardening seemed to improve fresh food access for everyone which is an important component of food justice. In schools with successful gardening programs, children and teachers were able to go home with produce, even in low income communities, and to gain food and nutrition literacy which is consistent with previous literature [55]. Farmers and gardeners in our second study also talked about their engagement to improve affordable fresh food access, in particular by voluntarily teaching their community members to grow their own food. In study 3 , people reported eating more fruits and vegetables since they started gardening, and $52 \%$ of our respondents said they now spent less money on purchasing fruits and vegetables. However, in each of our studies, a number of barriers limited the benefits of gardening on social inequalities. In particular, the lack of gardening knowledge prevented schools from implementing successful gardening programs and hindered our survey respondents' capacity to garden more. Similarly, the lack of knowledge was the \#1 barrier to gardening shared by our study 3 participants. This lack of knowledge among the general population is the result of both cultural norms that have long disvalued farming activities and knowledge, and of curriculums that-still today-do not regard food and nutrition literacy as fundamental competences. Additionally, people struggle with land access in urban environments, which adds another challenge, even for people who have some gardening knowledge. These results highlight the importance of general environment influences: without the proper policy support, it remains very difficult for gardening to deeply tackle social justice issues and its effects on well-being may be volatile. 
For this paper, we were able to observe potent but limited examples of the effects of gardening on racial inequalities. In our study 2 , minority farmers actively worked to reduce racial injustice by successfully providing trainings, mentorship, and fresh food access to their communities. However, racial injustice was rarely mentioned by other interview participants. In study 1 , no information on race was available. In our third study, only 16 people identified as minority and their results did not significantly differ from Caucasians but the sample is too small to make any conclusion. To remedy these limitations, future research should consider tailoring recruitment methods to different minority groups. For example, conducting interviews and surveys in Spanish would be relevant in the Arizona context. Additionally, further research could specifically seek to compare the lived experiences of white and minority gardeners to better understand the relationship between well-being and sustainable gardening across racial groups.

To conclude, this paper highlighted the importance of including food producers to the discussion on well-being and happiness. Our studies showed the effects that gardeningand especially gardening sustainably - can have on the five dimensions of the FWB framework, and on both hedonic and eudemonic well-being. Thus, the conversation on Food Well Being needs to go beyond food consumption and integrate food producing activities to better capture the food-related drivers of well-being. While conducting this research and exploring the effects of gardening on racial and social inequalities, it became clear across our three studies that food growing knowledge and activities do not benefit from a level of support commensurate to their contribution to society's well-being. At the risk of stating the obvious, we want to stress that there can be no type of food consumption without food production. Food producers, especially sustainable farmers and farmworkers, serve as a lifeline for all of us; this became very clear during the food shortages at the beginning of the COVID-19 pandemic. It is vital for our society to better value their role with policies that improves their situations, for example: fair prices, better land access and safe working conditions. It is also critical to recognize and value food growing competences, and to provide a solid education on the subject to everyone. In doing so, policy makers can contribute to enhancing food justice and happiness.

Author Contributions: Conceptualization, S.E.-S., E.G.G. and A.O.; methodology, S.E.-S., E.G.G. and A.O.; software, S.E.-S., E.G.G. and A.O.; formal analysis, S.E.-S. and E.G.G.; investigation, S.E.-S. and E.G.G.; resources, S.E.-S., E.G.G. and A.O.; data curation, S.E.-S., E.G.G. and A.O.; writing-original draft preparation, S.E.-S. and E.G.G.; writing-review and editing, E.G.G.; project administration, S.E.-S. and E.G.G.; funding acquisition, S.E.-S., E.G.G. and A.O. All authors have read and agreed to the published version of the manuscript.

Funding: This research was funded by the School of Sustainability at Arizona State University, and by personal funds.

Institutional Review Board Statement: The study was conducted according to the guidelines of the Declaration of Helsinki, and approved by the Institutional Review Board of Arizona State University (Study 1: protocol STUDY00008656 on 9/24/2018, Study 2: protocol STUDY00006391 on 6/13/2017, Study 3: protocol STUDY00013751 on 4/28/2021).

Informed Consent Statement: Informed consent was obtained from all subjects involved in the study.

Data Availability Statement: The data presented in this study are available on request from the corresponding author.

Acknowledgments: The authors thank all the participants who participated in this research, as well as the students and Hallie Eakin from the 2018 Food System Sustainability class at ASU. The authors also express their gratitude to Sarra Tekola, the Rocky Mountain Seed Foundation and Greg Peterson and the Urban Farm team for their support in our research study.

Conflicts of Interest: The authors declare no conflict of interest. 


\section{References}

1. IPES-Food. COVID-19 and the Crisis in Food Systems: Symptoms, Causes, and Potential Solutions; IPES-Food: Brussels, Belgium, 2020.

2. Acciai, F.; Belarmino, E.H.; Josephson, A.L.; Niles, M.T. Changes in Employment Status and Food Security among U.S. Households during the First Four Months of the COVID-19 Pandemic; College of Health Solutions, Arizona State University: Tempe, AZ, USA, 2020.

3. Theodorou, A.; Panno, A.; Carrus, G.; Carbone, G.A.; Massullo, C.; Imperatori, C. Stay Home, Stay Safe, Stay Green: The Role of Gardening Activities on Mental Health during the Covid-19 Home Confinement. Urban For. Urban Green. 2021, 61, 127091. [CrossRef]

4. Walljasper, C.; Polansek, T. Home Gardening Blooms around the World during Coronavirus Lockdowns; Reuters: London, UK, 2020.

5. Giraud, E. Urban Food Autonomy: The Flourishing of an Ethics of Care for Sustainability. Humanities 2021, 10, 13. [CrossRef]

6. Peterson, G. (Urban Farm). El Sayed Personal Communications, 2021.

7. Webber, J.; Hinds, J.; Camic, P.M. The Well-Being of Allotment Gardeners: A Mixed Methodological Study. Ecopsychology 2015, 7, 20-28. [CrossRef]

8. Vogt, C.A.; Cybil, K.; Sia, A. Urban Greening and Its Role in Fostering Human Wellbeing. In Greening Cities: Advances in 21st Century Human Settlements; Tan, P., Jim, C., Eds.; Springer: Singapore, 2017; pp. 95-111.

9. Block, L.G.; Grier, S.A.; Childers, T.L.; Davis, B.; Ebert, J.E.J.; Kumanyika, S.; Laczniak, R.N.; Machin, J.E.; Motley, C.M.; Peracchio, L.; et al. From Nutrients to Nurturance: A Conceptual Introduction to Food Well-Being. J. Public Policy Mark. 2011, 30, 5-13. [CrossRef]

10. Frentz, F. The Pursuit of Food Well-Being: The Mechanisms Behind Consumers' Food Well-Being, and Their Relevance for Food Retailing and Marketing; Swoboda, B., Foscht, T., Schramm-Klein, H., Eds.; Springer Gabler: Siegen, Germany, 2020.

11. Clatworthy, J.; Hinds, J.; Camic, P.M. Gardening as a Mental Health Intervention: A Review. Ment. Health Rev. J. 2013, 18, 214-225. [CrossRef]

12. Jepson, A. Gardening and wellbeing: A view from the ground. In Making and Growing: Anthropological Studies of Organisms and Artefacts; Hallam, E., Ingold, T., Eds.; Taylor \& Francis Group: Abingdon, UK, 2014; pp. 147-162, ISBN 9781409436423.

13. Pfeiffer, D.; Cloutier, S. Planning for Happy Neighborhoods. J. Am. Plan. Assoc. 2016, 82, 267-279. [CrossRef]

14. Gibbons, L.V.; Cloutier, S.A.; Coseo, P.J.; Barakat, A. Regenerative Development as an Integrative Paradigm and Methodology for Landscape Sustainability. Sustainability 2018, 10, 1910. [CrossRef]

15. Cloutier, S.; Karner, A.; Breetz, H.L.; Toufani, P.; Onat, N.; Patel, S.; Paralkar, S.; Berejnoi, E.; Morrison, B.A.; Papenfuss, J.; et al. Measures of a Sustainable Commute as a Predictor of Happiness. Sustainability 2017, 9, 1214. [CrossRef]

16. Dolan, P.; Peasgood, T.; Dixon, A.M.; Knight, M.; Phillips, D.; Tsuchiya, A.; White, M. Research on the Relationship between Well-Being and Sustainable Development; DEFRA: London, UK, 2006.

17. Barton, H.; Grant, M.; Guise, R. Shaping Neighbourhoods: A Guide for Health, Sustainability and Vitality; Spon Press: London, UK, 2003.

18. Colfer, C.J.P.; Brocklesby, M.A.; Diaw, C.; Etuge, P.; GÜNTER, M.; Harwell, E.; McDougall, C.; Porro, N.M.; Porro, R.; Prabhu, R.; et al. The BAG: Basic Assessment Guide for Human WellBeing; Center for International Forestry Research: Jakarta, Indonesia, 1998.

19. Pearce, B. DTI Sustainability and Business Competitiveness, Measuring the Benefit for Business Competitive Advantage from Social Responsibility and Sustainability; Center for Sustainable Development: London, UK, 2003.

20. O'Brien, L.; Claridge, J. Trees Are Company. In Social Science Research into Woodlands and the Natural Environment; Forestry Commission: Cardiff, Wales, 2001.

21. Wali, A.; Alvira, D.; Tallman, P.S.; Ravikumar, A.; Macedo, M.O. A New Approach to Conservation: Using Community Empowerment for Sustainable Well-Being. Ecol. Soc. 2017, 22. [CrossRef]

22. Metson, G.S.; Bennett, E.M. Phosphorus Cycling in Montreal's Food and Urban Agriculture Systems. PLoS ONE 2015, 10, e0120726. [CrossRef]

23. Gheitarani, N.; El-Sayed, S.; Cloutier, S.; Budruk, M.; Gibbons, L.; Khanian, M. Investigating the Mechanism of Place and Community Impact on Quality of Life of Rural-Urban Migrants. Int. J. Community Well-Being 2020, 18. [CrossRef]

24. Barrington-Leigh, C. Sustainability and Well-Being: A Happy Synergy. Development 2016, 59, 292-298. [CrossRef]

25. Helne, T. Well-Being for a Better World: The Contribution of a Radically Relational and Nature-Inclusive Conception of Well-Being to the Sustainability Transformation. Sustain. Sci. Pract. Policy 2021, 17, 221-231. [CrossRef]

26. Coulthard, S. What Does the Debate around Social Wellbeing Have to Offer Sustainable Fisheries? Curr. Opin. Environ. Sustain. 2012, 4, 358-363. [CrossRef]

27. Di Fabio, A. Positive Healthy Organizations: Promoting Well-Being, Meaningfulness, and Sustainability in Organizations. Front. Psychol. 2017, 8, 1938. [CrossRef] [PubMed]

28. Weidema, B.P.; Stylianou, K.S. Nutrition in the Life Cycle Assessment of Foods-Function or Impact? Int. J. Life Cycle Assess 2020, 25, 1210-1216. [CrossRef]

29. Fanzo, J.; Hunter, D.; Borelli, T.; Mattei, F. (Eds.) Diversifying Food and Diets: Using Agricultural Biodiversity to Improve Nutrition and Health, 1st ed.; Issues in agricultural biodiversity; Earthscan from Routledge: London, UK; New York, NY, USA, 2013; ISBN 978-1-84971-456-3.

30. Floud, R.; Fogel, R.W.; Harris, B.; Hong, S.C. The Changing Body: Health, Nutrition, and Human Development in the Western World since 1700; Cambridge University Press: Cambridge, UK, 2011; ISBN 978-1-139-50080-7. 
31. Owen, L.; Corfe, B. The Role of Diet and Nutrition on Mental Health and Wellbeing. Proc. Nutr. Soc. 2017, 76, 425-426. [CrossRef]

32. Firth, J.; Gangwisch, J.E.; Borsini, A.; Wootton, R.E.; Mayer, E.A. Food and Mood: How Do Diet and Nutrition Affect Mental Wellbeing? BMJ 2020, 369, m2382. [CrossRef]

33. Atkinson, W. The Structure of Food Taste in 21st Century Britain. Br. J. Sociol. 2021. [CrossRef] [PubMed]

34. Spackman, C.; Lahne, J. Sensory Labor: Considering the Work of Taste in the Food System. Food Cult. Soc. 2019, 22, 142-151. [CrossRef]

35. Dini, I.; Laneri, S. Spices, Condiments, Extra Virgin Olive Oil and Aromas as Not Only Flavorings, but Precious Allies for Our Wellbeing. Antioxidants 2021, 10, 868. [CrossRef] [PubMed]

36. Diamond, K. Opinion I The Strange Grief of Losing My Sense of Taste. The New York Times, 2020.

37. Deci, E.L.; Ryan, R.M. Hedonia, Eudaimonia, and Well-Being: An Introduction. J. Happiness Stud. Interdiscip. Forum Subj. Well-Being 2008, 9, 1-11. [CrossRef]

38. Scott, T.L.; Masser, B.M.; Pachana, N.A. Exploring the Health and Wellbeing Benefits of Gardening for Older Adults. Ageing Soc. 2015, 35, 2176-2200. [CrossRef]

39. Blair, D. The Child in the Garden: An Evaluative Review of the Benefits of School Gardening. J. Environ. Educ. 2009, 40, 15-38. [CrossRef]

40. Skelly, S.M.; Bradley, J.C. The Importance of School Gardens as Perceived by Florida Elementary School Teachers. Hord Technol. 2000, 10, 229-231. [CrossRef]

41. Baker, L.E. Tending Cultural Landscapes and Food Citizenship in Toronto's Community Gardens. Geogr. Rev. 2005, 3, 305-325. [CrossRef]

42. Wilson, E.O. Biophilia; Harvard University Press: Cambridge, MA, USA, 1984.

43. Smith, J.P.; Meerow, S.; Turner, B.L. Planning Urban Community Gardens Strategically through Multicriteria Decision Analysis. Urban For. Urban Green. 2021, 58, 126897. [CrossRef]

44. Malberg Dyg, P.; Wistoft, K. Wellbeing in School Gardens-the Case of the Gardens for Bellies Food and Environmental Education Program. Environ. Educ. Res. 2018, 24, 1177-1191. [CrossRef]

45. Taylor, N.; Wright, J.; O'Flynn, G. Cultivating 'Health' in the School Garden. Sport Educ. Soc. 2021, 26, 403-416. [CrossRef]

46. Wiseman, J.; Murphy, J.; Hewitt-Taylor, J. Changing Food Culture for Food Wellbeing. Int. J. Home Econ. 2018, 11, 20-33.

47. Vaughn, R. On COVID-19: Food and/as Mutualism. Gastron. J. Food Cult. 2020, 20, 108-110. [CrossRef]

48. Horst, M.; Mcclintock, N.; Hoey, L. The Intersection of Planning, Urban Agriculture, and Food Justice: A Review of the Literature. J. Am. Plan. Assoc. 2017, 83, 277-295. [CrossRef]

49. Fong, L.M. Sojourners and Settlers: The Chinese Experience in Arizona. J. Ariz. Hist. 1980, 21, 227-256. [CrossRef]

50. Williams, J.M.; Holt-Giménez, E. Land Justice: Re-Imagining Land, Food, and the Commons in the United States; Williams, J.M., Holt-Giménez, E., Eds.; Food First Books: Oakland, CA, USA, 2017; ISBN 9780935028195.

51. Alkon, A.H.; Agyeman, J. Overview. In Cultivating Food Justice: Race, Class and Sustainability; Alkon, A.H., Agyeman, J., Eds.; MIT Press: Cambridge, MA, USA, 2011; pp. 13-15.

52. Milbourne, P. Everyday (in)Justices and Ordinary Environmentalisms: Community Gardening in Disadvantaged Urban Neighbourhoods. Local Environ. 2012, 17, 943-957. [CrossRef]

53. Mello, C.; King, L.O.; Adams, I. Growing Food, Growing Consciousness: Gardening and Social Justice in Grand Rapids, Michigan. Cult. Agric. Food Environ. 2017, 39, 143-147. [CrossRef]

54. Barron, J. Community Gardening: Cultivating Subjectivities, Space, and Justice. Local Environ. 2017, 22, 1142-1158. [CrossRef]

55. Bleasdale, T. Gardens of Justice: Food-Based Social Movements in Underserved, Minority Communities. Ph.D. Thesis, Arizona State University, Tempe, AZ, USA, 2015; p. 289.

56. De Wilde, M.; Koopman, W.; Mol, A. Clean in Times of Covid-19: On Hygiene and Pollution. Somatosphere 2020, $2020,1-6$.

57. Cutts, B.B.; London, J.K.; Meiners, S.; Schwarz, K.; Cadenasso, M.L. Moving Dirt: Soil, Lead, and the Dynamic Spatial Politics of Urban Gardening. Local Environ. 2017, 22, 998-1018. [CrossRef]

58. Albright, R. 2025 Food Action Plan; City of Phoenix: Phoenix, AZ, USA, 2020.

59. Dutko, P.; Ver Ploeg, M.; Farrigan, T. Characteristics and Influential Factors of Food Deserts; USDA Economic Research Services: Washington, DC, USA, 2012.

60. Mack, E.A.; Tong, D.; Credit, K. Gardening in the Desert: A Spatial Optimization Approach to Locating Gardens in Rapidly Expanding Urban Environments. Int. J. Health Geogr. 2017, 16, 37. [CrossRef]

61. Bernard, H.R.; Wutich, A.; Ryan, G.W. Analyzing Qualitative Data: Systematic Approaches, 2nd ed.; SAGE Publications Ltd.: London, UK, 2017.

62. Allen, P. Realizing Justice in Local Food Systems. Camb. J. Reg. Econ. Soc. 2010, 3, 295-308. [CrossRef]

63. Beumer, C. Show Me Your Garden and I Will Tell You How Sustainable You Are: Dutch Citizens' Perspectives on Conserving Biodiversity and Promoting a Sustainable Urban Living Environment through Domestic Gardening. Urban For. Urban Green. 2018, 30, 260-279. [CrossRef]

64. Mollison, B. Permaculture: A Designers' Manual; Ten Speed Press: Berkeley, CA, USA, 1988; ISBN 978-0-908228-01-0.

65. Hervás, G.; Vázquez, C. Construction and Validation of a Measure of Integrative Well-Being in Seven Languages: The Pemberton Happiness Index. Health Qual. Life Outcomes 2013, 11, 66. [CrossRef] [PubMed] 
66. Missoula Food Bank. Food Access and Affordability Survey; Missoula Food Bank: Missoula, Montana, 2016.

67. Soga, M.; Gaston, K.J.; Yamaura, Y. Gardening Is Beneficial for Health: A Meta-Analysis. Prev. Med. Rep. 2017, 5, 92-99. [CrossRef]

68. Thompson, R. Gardening for Health: A Regular Dose of Gardening. Clin. Med. 2018, 18, 201-205. [CrossRef] [PubMed] 